\title{
Protective Effect of High Density Lipoprotein Associated Paraoxonase Inhibition of the Biological Activity of Minimally Oxidized Low Density Lipoprotein
}

\author{
Andrew D. Watson, ${ }^{\star}$ Judith A. Berliner, ${ }^{\star \ddagger}$ Susan Y. Hama, ${ }^{\ddagger}$ Bert N. La Du, $"$ Kym F. Faull, ${ }^{\S}$ Alan M. Fogelman, ${ }^{\ddagger}$ and \\ Mohamad Navab $\neq$ \\ *Departments of Pathology, ${ }^{\ddagger}$ Medicine, and Psychiatry \& Biobehavioral Sciences and the ${ }^{\S}$ Neuropsychiatric Institute, University of \\ California, Los Angeles, California 90095-1732; and "Department of Pharmacology, University of Michigan, Ann Arbor, Michigan \\ 48104
}

\section{Abstract}

Our group has previously demonstrated that oxidized phospholipids in mildly oxidized LDL (MM-LDL) produced by oxidation with lipoxygenase, iron, or cocultures of artery wall cells increase monocyte-endothelial interactions and this sequence of events is blocked by HDL. To obtain further insight into the mechanism by which HDL abolishes the activity of MM-LDL we investigated the effect of the HDLassociated ester hydrolase paraoxonase (PON). Treatment of MM-LDL with purified PON significantly reduced the ability of MM-LDL to induce monocyte-endothelial interactions. Inactivation of PON by pretreating HDL with heat or EDTA reduced the ability of HDL to inhibit LDL modification. HPLC analysis of phospholipids isolated from MMLDL before and after treatment with purified PON showed that the $270 \mathrm{~nm}$ absorbance of phospholipids was decreased, while no effect was observed on 235 nm absorbance. Oxidized 1-palmitoyl-2-arachidonoyl-sn-glycero-3-phosphorylcholine (Ox-PAPC) and specific fractions of Ox-PAPC isolated by HPLC induced the same monocyte-endothelial interactions as did MM-LDL. Biologically active and inactive HPLC fractions of Ox-PAPC were compared by fast atom bombardment-mass spectrometry which revealed that active fractions possessed ions with a mass to change ratio greater than native PAPC by multiples of $16 \mathrm{D}$ suggesting the addition of 3 and 4 oxygen atoms to PAPC. Comparison of Ox-PAPC by fast atom bombardment-mass spectrometry before and after PON treatment showed that PON destroyed these multi-oxygenated molecules found in biologically active fractions of Ox-PAPC. These results suggest that PON in HDL may protect against the induction of inflammatory responses in artery wall cells by destroying biologically active lipids in mildly oxidized LDL. (J. Clin. Invest. 1995. 96:2882-2891.) Key words: LDL modification • lipid peroxidation - monocyte adhesion - fast atom bombardment-mass spectrometry • electrospray-mass spectrometry

Address correspondence to Andrew D. Watson, Department of Pathology, Center for the Health Sciences, Room 13-186, UCLA Medical School, Los Angeles, CA 90095-1732. Phone: 310-825-2436; FAX: 310-206-5178; E-mail: awatson@pathology.medsch.ucla.edu

Received for publication 30 January 1995 and accepted in revised form 23 August 1995.

J. Clin. Invest.

(c) The American Society for Clinical Investigation, Inc. $0021-9738 / 95 / 12 / 2882 / 10 \quad \$ 2.00$

Volume 96, December 1995, 2882-2891

\section{Introduction}

Oxidation of LDL appears to play an important role in the development and progression of the atherosclerotic lesion (13 ). Artery wall cells can produce oxidative species via multiple pathways which "seed" LDL trapped in the subendothelial space and initiate lipid oxidation (4-6). The biological properties of oxidized LDL in vitro appear to be dependent on the degree to which the lipid and protein components are oxidized. Mildly oxidized LDL (MM-LDL) ${ }^{1}$ induces the activation of the nuclear transcription factor NF $\kappa$ B via a cAMP-dependent mechanism (7) and consequently induces endothelial cells to express monocyte-specific chemoattractants $(8,9)$, adhesion molecules (10), and colony stimulating factors (11). Highly oxidized LDL (Ox-LDL) is cytotoxic to artery wall cells (1214) and is taken up by the scavenger receptor on macrophages (15-17). In humans, plasma levels of HDL are inversely correlated with the risk of clinically significant coronary events ( 18 , 19). Moreover, in vitro experiments have demonstrated that HDL inhibits LDL modification $(9,14,20,21)$. Despite convincing evidence for the presence of oxidized LDL in the blood vessel wall $(22-24)$ and the antiatherogenic properties of HDL, the interaction between these two lipoprotein particles is not well understood.

Human serum paraoxonase (PON) is a calcium-dependent HDL-associated ester hydrolase that catalyzes the hydrolysis of organophosphates, aromatic carboxylic acid esters, and carbamates (25). The initial measurement of its activity was performed using synthetic substrates, therefore, an interesting, and as yet unresolved question, is what role PON plays in metabolizing substrates formed in vivo. PON is tightly associated with apolipoprotein A-I in HDL and has the highest activity in the liver and blood (25). Serum PON levels vary widely between different animal species (26) and among humans (27). Individuals with familial hypercholesterolemia and insulin-dependent diabetes mellitus have significantly lower serum levels of PON than do control individuals (28). Low levels of HDL-associated esterases are also correlated with susceptibility to myocardial infarction, fish eye disease, and Tangier disease $(29,30)$. HDLassociated PON has been reported to inhibit copper-induced lipid peroxide generation in LDL (31). Our laboratory has recently shown that platelet activating factor-acetylhydrolase (PAF-AH), a phospholipase $\mathrm{A}_{2}$ that hydrolyzes short chain acyl groups and longer chain aldehydes esterified to the $s n-2$ position

1. Abbreviations used in this paper: BHT, butylated hydroxytoluene; CM-LDL, coculture-modified LDL; $\mathrm{m} / \mathrm{z}$ mass to charge ratio; MMLDL, mildly oxidized LDL; Ox-PAPC, oxidized 1-palmitoyl-2-arachidonoyl-sn-glycero-3-phosphorylcholine; PAF-AH, platelet-activating factor protein-1; PAPC, 1-palmitoyl-2-arachidonoyl-sn-glycero-3-phosphorylcholine; PC, phosphatidylcholine; PON, paraoxonase. 
of phospholipids, plays an important role in modulating the biological activity of MM-LDL (32). Based on the studies reported here we hypothesize that PAF-AH and PON in HDL may work in concert to reduce the content of biologically active oxidized phospholipids in MM-LDL and, in part, account for the inverse relationship between HDL and the risk for clinical events resulting from atherosclerosis.

\section{Methods}

Materials. Tissue culture media, serum, and supplements were obtained from sources previously reported $(9,10)$. Acetonitrile, chloroform, hexane, methanol, 2-propanol, triethylamine (all HPLC grade or better) were obtained from Fisher Scientific, Pittsburgh, PA. Gelatin (endotoxin-free, tissue culture grade, \# G 9391) and butylated hydroxytoluene (BHT) were obtained from Sigma Chemical Co., St. Louis, MO. Authentic L- $\alpha$-1-palmitoyl-2-arachidonoyl-sn-glycero-3-phosphorylcholine (PAPC) was obtained from Avanti Polar Lipids, Inc., Alabaster, AL and $\mathrm{L}-\alpha$-1-palmitoyl-2- $\left[1-{ }^{14} \mathrm{C}\right]$-arachidonoyl-sn-glycero-3-phosphorylcholine was purchased from DuPont NEN, Boston, MA. Amino and $\mathrm{C}_{18}$ solid phase extraction columns were obtained from J.T. Baker, Phillipsburg, NJ. Transwells and chamber slides were obtained from Costar Corp., Cambridge, MA. Centricons were obtained from Amicon Corp., Beverly, MA. PON was isolated from human or rabbit plasma as described (33).

Endothelial cell cultures. Rabbit aortic endothelial cells (RAEC) at passages 9-17 and human aortic endothelial cells (HAEC) at passages 4-7 were cultured as described $(9,10)$. Porcine aortic endothelial cells (PAEC) were isolated by enzymatic digestion according to the method of Rosenthal et al. (34) with described modifications (32).

Cocultures. HAEC and human aortic smooth muscle cells (HASMC) were isolated and prepared as previously described $(9,32$, 35 ). Blood monocytes were obtained from a large pool of healthy donors using a modification of the Recalde procedure (36).

Lipoprotein isolation and modification. LDL $(d=1.019-1.069$ grams $/ \mathrm{ml})$ and $\mathrm{HDL}(d=1.069-1.210$ grams $/ \mathrm{ml})$ were isolated from the sera of normal blood donors by density gradient ultracentrifugation as described (37) and stored at $4^{\circ} \mathrm{C}$ until use within 1-2 wk of isolation. Lipoprotein concentration was expressed in terms of protein content throughout this report. Mildly oxidized LDL was produced either by dialysis at $5 \mathrm{mg}$ protein $/ \mathrm{ml}$ in $6 \mu \mathrm{M} \mathrm{FeSO}_{4} \cdot 7 \mathrm{H}_{2} \mathrm{O}$ for $48-72 \mathrm{~h}$ at room temperature, by incubation at $1 \mathrm{mg}$ protein/ml with soybean lipoxygenase (SLO) bound to CNBr-activated Sepharose beads with linoleic acid $(187 \mathrm{mM})$ in $1 \mathrm{ml} \mathrm{PBS}$ for $24 \mathrm{~h}$ at $37^{\circ} \mathrm{C}(32)$, or by incubation with human endothelial/smooth muscle cell cocultures for $8-24 \mathrm{~h}$ at $37^{\circ} \mathrm{C}$ (9). SLO was removed by centrifugation after oxidation had occurred. Oxidation was terminated by the addition of EDTA and BHT at 100 $\mu \mathrm{M}$ and $0.3 \mathrm{mM}$, respectively. EDTA was excluded in experiments using PON. The concentration of bacterial endotoxin in medium containing each agonist was $<50 \mathrm{pg} / \mathrm{ml}$ (determined by chromogenic assay) which is $\sim 50$-fold less than that required to induce monocyte binding to endothelial cells.

Lipid extraction. Lipids were extracted using a modification of the method of Bligh and Dyer (38) as described (32). Phospholipids, free fatty acids, and neutral lipids were separated by the method of Kaluzny et al. (39) utilizing amino solid phase extraction (spe) chromatography (32). Phospholipid recovery typically ranged between $95-98 \%$ as determined by using 1-palmitoyl-2- $\left[1-{ }^{14} \mathrm{C}\right]$-arachidonoyl-sn-glycero-3-phosphorylcholine as an internal standard. Lipid fractions not used immediately were dried under nitrogen, resuspended in chloroform containing $0.01 \%$ BHT, covered with argon, and stored at $-20^{\circ} \mathrm{C}$.

High performance liquid chromatography. Analytical HPLC was performed by injecting isolated phospholipids (resuspended in chloroform) onto a silica column (Spherisorb, $150 \mathrm{~mm} \times 4.6 \mathrm{~mm}, 5 \mu \mathrm{m}$; Alltech Associates, Inc., Deerfield, IL) and eluting isocratically with a mobile solvent of acetonitrile/methanol/water $(79: 8: 13, \mathrm{vol} / \mathrm{vol} / \mathrm{vol})$ at $1.0 \mathrm{ml} / \mathrm{min}$. Preparative HPLC was performed by injecting the total lipid extract onto a silica column (Adsorbosphere, $250 \mathrm{~mm} \times 10 \mathrm{~mm}$, $5 \mu \mathrm{m}$; Alltech Associates, Inc.) and eluting isocratically with either acetonitrile/methanol/water $(79: 8: 13, \mathrm{vol} / \mathrm{vol} / \mathrm{vol})$ or hexane/isopropanol/water (39:59:12, vol/vol/vol) at $5.0 \mathrm{ml} / \mathrm{min}$. UV absorbance was detected with a diode array detector (L-3000; Hitachi, Ltd., Tokyo, Japan) scanning from 200 to $350 \mathrm{~nm}$. In some cases, fractions were collected from the column under sterile conditions, dried to a residue under nitrogen at $37^{\circ} \mathrm{C}$, and either resuspended in tissue culture medium for monocyte adhesion/transmigration assays or analyzed by mass spectrometry.

Fast atom bombardment-mass spectrometry. Fast atom bombardment spectra were obtained with a VG ZAB-SE instrument (VG Analytical, Manchester, United Kingdom) using an 11/250 data system; an 8$\mathrm{kV}$ acceleration potential; xenon bombarding gas at $8 \mathrm{kV}$ and $1 \mathrm{~mA}$; and the instrument set at a mass resolution of $1,000(\mathrm{M} / \Delta \mathrm{M}, 10 \%$ valley). Aliquots (1-2 $\mu \mathrm{l})$ of lipid suspended in chloroform were applied to the static probe tip onto which had been placed 1-2 $\mu \mathrm{l}$ of $m$ nitrobenzyl alcohol. Data were collected by scanning from mass to charge ratio $(\mathrm{m} / \mathrm{z}) 1,000$ to 400 and an average spectrum was produced from six to eight independent scans. The data were mass measured using cesium iodide ion clusters for calibration. The mass accuracies of authentic phospholipid standards under these conditions were typically less than $\pm 0.5 \mathrm{D}$.

Electrospray mass spectrometry. Electrospray mass spectrometry was performed with a PE SCIEX API III Biomolecular Mass Analyzer (Perkin-Elmer Corp., Norwalk, CT). Total lipid extracts from the equivalent of $5 \mathrm{mg}$ protein were separated by preparative HPLC and fractions were dried and resuspended in $1 \mathrm{ml}$ of $50 \%$ acetonitrile $0.1 \%$ formic acid. Aliquots $(20 \mu \mathrm{l})$ were injected at a flow rate of $20 \mu \mathrm{l} / \mathrm{min}$ into the ion source of the mass spectrometer which was scanning from $\mathrm{m} / \mathrm{z}$ 150 to 1,000 ( step size of $0.1 \mathrm{D}$, scan speed of $5 \mathrm{~s}$ ). Signals were mass measured by means of the multiply charged ion series from the separate introduction of polypropylene glycol for calibration. Under standard conditions the accuracy of these mass measurements is $< \pm 0.05 \mathrm{D}$. Selected ion chromatograms were produced by software supplied by PE SCIEX.

Monocyte adhesion/transmigration assays. These studies were performed essentially as described previously $(7,9,10,32)$. Briefly, for monocyte adhesion assays human aortic endothelial cells were incubated with test medium for $4 \mathrm{~h}$ at $37^{\circ} \mathrm{C}$. A suspension of human monocytes were added for $15 \mathrm{~min}$ and nonadherent monocytes were removed. Bound monocytes were counted and expressed as monocytes/microscopic field. For monocyte transmigration studies, cocultures were treated with native LDL in the absence or presence of various test compounds for $8-24 \mathrm{~h}$ at $37^{\circ} \mathrm{C}$. The coculture supernatants were subsequently transferred to untreated cocultures and incubated for an additional $24 \mathrm{~h}$. Test medium was removed and human monocytes were added for $45-90 \mathrm{~min}$ at $37^{\circ} \mathrm{C}$. Loosely adherent monocytes were removed and cocultures were fixed. Subendothelial monocytes were enumerated under a magnification of 625. Data were analyzed using model 1 ANOVA.

Enzyme activity assays. PAF-AH activity was determined by using 2-[acetyl- $\left.{ }^{3} \mathrm{H}\right]$ PAF as a substrate. The $\left[{ }^{3} \mathrm{H}\right]$-acetate generated after $\boldsymbol{s n}$ 2 hydrolysis was separated from labeled substrate by solid phase extraction chromatography and quantitated by liquid scintillation as described previously (40). Enzymic activity is expressed in micromoles hydrolyzed/min per milligram protein after appropriate corrections. PON activity was determined using paraoxon as the substrate by measuring the increase in the absorbance at $412 \mathrm{~nm}$ due to formation of 4-nitrophenol. Activity was measured in $50 \mathrm{nM}$ Tris/HCl buffers at $\mathrm{pH} 7.4$ and 8.0 , and in $50 \mathrm{nM}$ glycine $/ \mathrm{NaOH}$ at $\mathrm{pH} 10.5$. The sample to be tested was added to start the reaction and the increase in absorbance at $\mathbf{4 1 2}$ $\mathrm{nm}$ was recorded (33). The quantity of 4-nitrophenol formed was calculated from the molar extinction coefficients at $\mathrm{pH} 7.4,8.0$, and 10.5 which were $12,80017,000$, and $18,290 \mathrm{M}^{-1} \mathrm{~cm}^{-1}$, respectively. Blanks contained substrate without the lipoprotein sample or enzyme. $1 \mathrm{U}$ of PON activity is defined as $1 \mathrm{nmol}$ of 4-nitrophenol formed per min under the above assay conditions. The enzyme activity was also measured in 

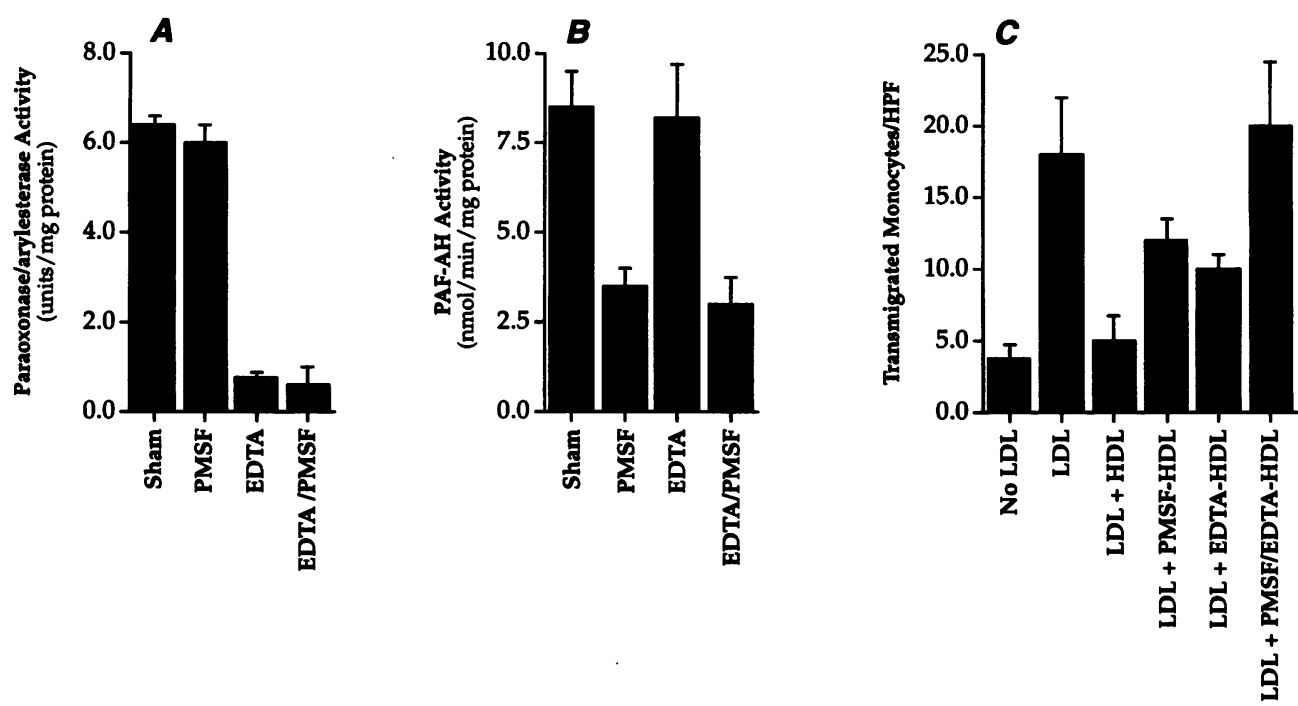

Figure 1. Effect of inactivation of paraoxonase and PAF-acetylhydrolase in HDL. HDL ( $1.0 \mathrm{mg}$ / $\mathrm{ml}$ ) in PBS was incubated with buffer alone (Sham), $3.0 \mathrm{mM}$ EDTA (EDTA), 3.0 mM PMSF $(P M S F)$, or both EDTA and PMSF (EDTA/PMSF) for $90 \mathrm{~min}$ at $37^{\circ} \mathrm{C}$ with gentle mixing under argon. HDL was reisolated to remove the unassociated EDTA or PMSF. The paraoxonase/arylesterase activity $(A)$ and PAF-AH activity $(B)$ of the treated HDL was determine as described in Methods. Values are mean \pm SD of triplicate measurements. HDL preparations were then tested for the ability to protect against LDL modification $(C)$. Artery wall cocultures were incubated with LDL

$(350 \mu \mathrm{g} / \mathrm{ml})$ in the absence or presence of HDL $(500 \mu \mathrm{g} / \mathrm{ml})$ that had been treated with EDTA (EDTA-HDL), PMSF (PMSF-HDL), or both EDTA and PMSF (EDTA/PMSF-HDL), followed by dialysis of HDL. Monocyte transmigration assays were conducted as described in Methods. Values are mean \pm SD of number of monocytes in 12 fields from four wells in each treatment. This figure is representative of three independent experiments.

an arylesterase assay (33). To a cuvette was added $1.0 \mathrm{mM}$ phenylacetate in $20 \mathrm{mM}$ Tris $/ \mathrm{HCl} \mathrm{pH} 8.0$. The reaction was initiated by the addition of the enzyme solution or the lipoprotein samples and the increase in absorbance at $270 \mathrm{~nm}$ was recorded. Blanks were included to correct for the spontaneous hydrolysis of phenylacetate. Enzymatic activity was calculated from the molar extinction coefficient $1,310 \mathrm{M}^{-1}$ $\mathrm{cm}^{-1}$. A unit of arylesterase activity is defined as $1 \mu \mathrm{mol}$ phenylacetate hydrolyzed per min under the above conditions.

Enzyme inactivation and supplementation of $H D L$. For inactivation of PON, HDL ( $1.0 \mathrm{mg} / \mathrm{ml}$ in PBS) was incubated with $3.0 \mathrm{mM}$ EDTA
$\boldsymbol{A}$

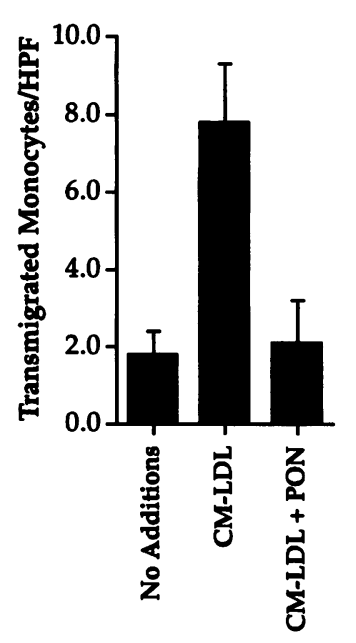

B

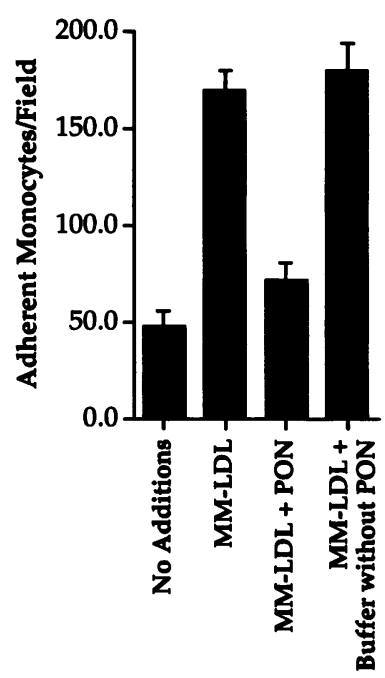

Figure 2. Effect of paraoxonase on the biological activity of mildly oxidized LDL. Coculture modified LDL $(A)$ or enzymatically modified LDL $(B)$ was incubated with purified human PON $(4-6 \mu \mathrm{g} / \mathrm{ml})$ for 14 $h$ at $37^{\circ} \mathrm{C}$ and tested for the ability to induce endothelial cells to bind monocytes and produce monocyte chemoattractants. $C M-L D L$, coculture modified LDL; $M M-L D L$, enzymatically modified LDL; PON PONtreated; $H P F$, high power field. at $37^{\circ} \mathrm{C}$ for $90 \mathrm{~min}$ with gentle mixing under argon. For inactivation of PAF-AH, HDL was incubated with $3.0 \mathrm{mM}$ PMSF as above. HDL was subsequently reisolated in an ultracentrifuge or by using $100,000 \mathrm{~mol}$ wt cut off Centricons. The effect of heat inactivation was tested by incubating the enzyme solution at $56^{\circ} \mathrm{C}$ for $10 \mathrm{~min}$ before the assay (41).

Other procedures. Measurement of cell protein content and those of lipoproteins were performed by microtiter plate assay based on the method of Lowry et al. (42).

\section{Results}

Inactivation of paraoxonase and PAF-acetylhydrolase in $H D L$. HDL was pretreated with buffer, EDTA (3.0 mM), PMSF (3.0 $\mathrm{mM}$ ), or both EDTA and PMSF for $90 \mathrm{~min}$ at $37^{\circ} \mathrm{C}$. HDL was reisolated and tested for paraoxonase/arylesterase activity, PAF-AH activity, and the ability to prevent LDL modification in a monocyte transmigration assay. The paraoxonase/arylesterase activity associated with HDL was reduced from $6.50 \pm 0.22 \mathrm{U} /$ $\mathrm{mg}$ protein to $0.59 \pm 0.14 \mathrm{U} / \mathrm{mg}$ protein by EDTA but was not affected by PMSF (Fig. $1 A$ ). Conversely, EDTA had no effect on the PAF-AH activity in HDL, but PMSF reduced PAF-AH activity by $\sim 60 \%$ (Fig. $1 \mathrm{~B}$ ). Fig. $1 \mathrm{C}$ illustrates the possible interdependence of these two enzymes in HDL to prevent LDL modification by artery wall cells. As shown previously $(9,35)$, LDL modified by incubation with cocultures $(L D L)$ induced monocyte transmigration which was completely inhibited if HDL was present during modification $(L D L+H D L)$. Selective inhibition of PON $(L D L+E D T A-H D L)$ or PAF-AH $(L D L$ $+P M S F-H D L$ ) partially decreased the ability of HDL to protect against LDL modification and subsequent monocyte transmigration (Fig. $1 C$ ). However, inactivation of both enzyme systems by pretreatment of HDL with both EDTA and PMSF ( $L D L$ $+E D T A / P M S F-H D L)$ resulted in an HDL preparation that exhibited no protection against LDL modification. Similarly, $\mathrm{HDL}$ which had been heated at $56^{\circ} \mathrm{C}$ for $30 \mathrm{~min}$ to inactivate PON could not completely protect against the modification of 

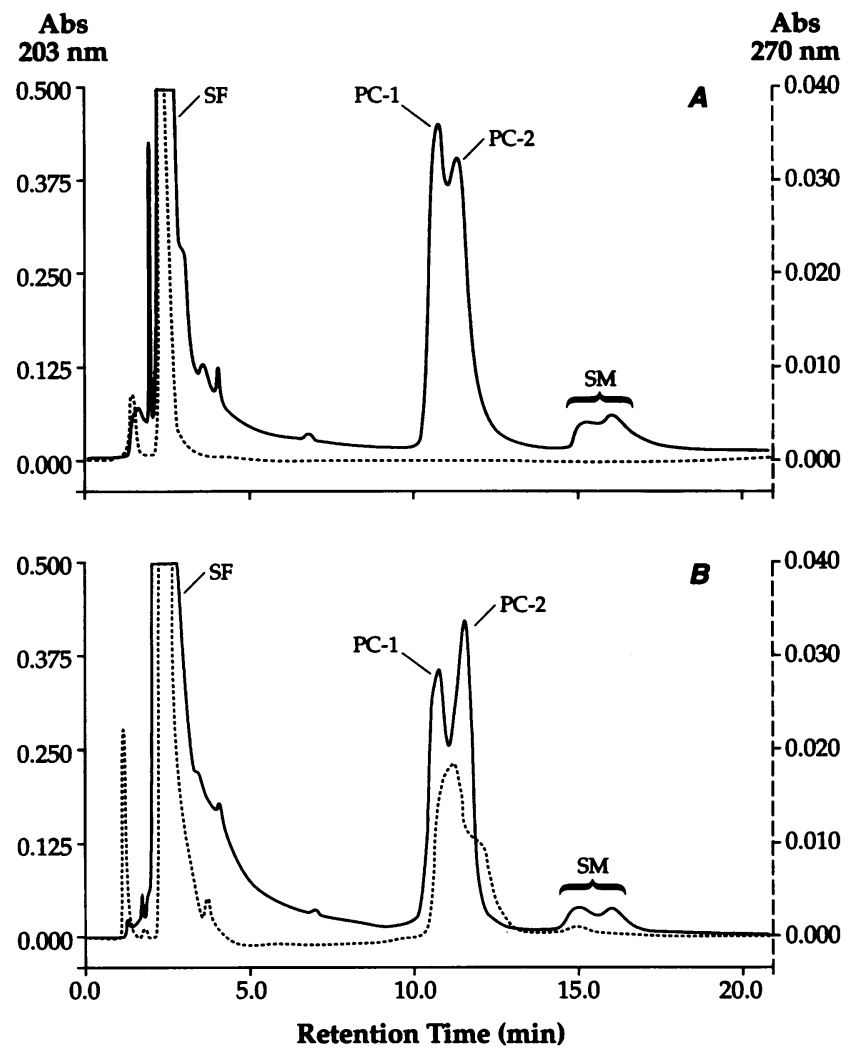

Figure 3. Effect of coculture modification on LDL phospholipids. Lipids were extracted with chloroform/methanol $(2: 1)+0.01 \%$ BHT and phospholipids separated by solid phase extraction chromatography as described in Methods. Phospholipids from native LDL $(A)$ and coculture modified LDL $(B)$ were analyzed by normal phase HPLC. UV absorbance was monitored at $203 \mathrm{~nm}$ (solid line) and $270 \mathrm{~nm}$ (dotted line ). $S F$, solvent front; $P C-1$, arachidonic acid-rich phosphatidylcholine; $P C-2$, linoleic acid-rich phosphatidylcholine; $S M$, sphingomyelin.

LDL and subsequent monocyte transmigration (data not shown ).

Effect of paraoxonase on the biological activity of mildly oxidized- $L D L$. Mildly oxidized-LDL produced in vitro with oxidative enzymes (Fig. $2 A$ ) or in vivo by incubation with cocultures (Fig. $2 \mathrm{~B}$ ) was incubated with purified PON at $37^{\circ} \mathrm{C}$ for $14 \mathrm{~h}$. Regardless of the method used to produce MM-LDL, treatment with PON reduced the ability of MM-LDL to induce monocyte binding and transmigration. MM-LDL incubated in the presence of the buffer in which PON was suspended (but without PON) had no effect on monocyte adhesion induced by MM-LDL (Fig. $2 B$ ). Controls to which EDTA and PMSF were added in the absence of lipoproteins had no effect on LDL oxidation or biological activity. Similar results were obtained with PON isolated from human and rabbit plasma both of which produced a single band on polyacrylamide gel electrophoresis.

$H P L C$ analysis of mildly oxidized-LDL. Phospholipids from LDL were analyzed before and after modification by incubation for $24 \mathrm{~h}$ with cocultures of human artery wall cells. Phospholipids extracted from MM-LDL possessed increased UV absorbance at $270 \mathrm{~nm}$ compared to unoxidized LDL from the same donor (Fig. 3). As noted before (32), under these HPLC conditions phosphatidylcholine (PC) elutes as a bimodal peak at $203 \mathrm{~nm}$ between 10.0 and $12.5 \mathrm{~min}$ and the first of these
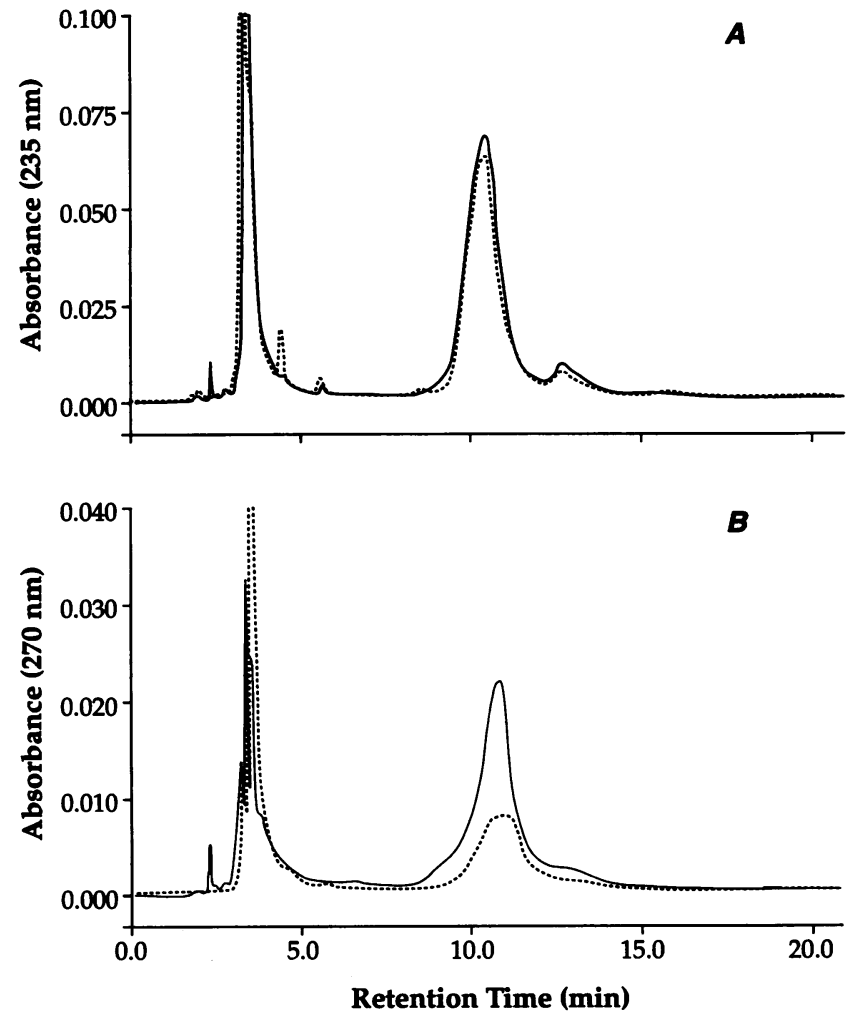

Figure 4. Effect of paraoxonase on phospholipids from coculture modified LDL. Coculture modified LDL was incubated with purified PON for $14 \mathrm{~h}$ at $37^{\circ} \mathrm{C}$. Lipids were extracted from PON-treated (dotted line) and sham-treated (solid line) CM-LDL and phospholipids were isolated by solid phase extraction chromatography. Phospholipids were separated by HPLC while detecting absorbance at $235 \mathrm{~nm}(A)$ and $270 \mathrm{~nm}(B)$.

peaks (PC-1) was decreased after mild oxidation. PC-1 was enriched in arachidonic acid-containing phosphatidylcholine as determined by the retention time of standard PAPC (which coelutes with PC-1) and confirmed by gas chromatographymass spectrometry of fatty acid methyl esters produced from phospholipids collected during elution of PC-1 and PC-2 (data not shown). The increase in $270 \mathrm{~nm}$ absorbance was likely due to the formation of carbonyl groups or conjugated trienes associated with polyunsaturated fatty acid (PUFA) in LDL phospholipids.

Since we have previously shown that oxidized phospholipids in MM-LDL are responsible for its biological activity (10, 32,43 ), we compared the HPLC chromatograms of phospholipids isolated from coculture modified LDL before and after PON treatment. Lipids were extracted from coculture conditioned medium and phospholipids were isolated by solid phase extraction chromatography as described (32). Phospholipids were suspended in chloroform and analyzed by normal phase analytical HPLC while scanning UV absorbance between 200 and $350 \mathrm{~nm}$ with a diode array detector. Fig. 4 displays HPLC chromatograms of phospholipids from coculture modified LDL at 235 and $270 \mathrm{~nm}$ before and after incubation with PON at $37^{\circ} \mathrm{C}$ for $14 \mathrm{~h}$. Treatment of CM-LDL with PON had little effect on the $235 \mathrm{~nm}$ absorbance of phosphatidylcholine (Fig. $4 \mathrm{~A}$ ), however, PON treatment greatly reduced the $270 \mathrm{~nm}$-absorbing material associated with CM-LDL phosphatidylcholine (Fig. 4 $B)$. These results indicate that PON may selectively recognize 

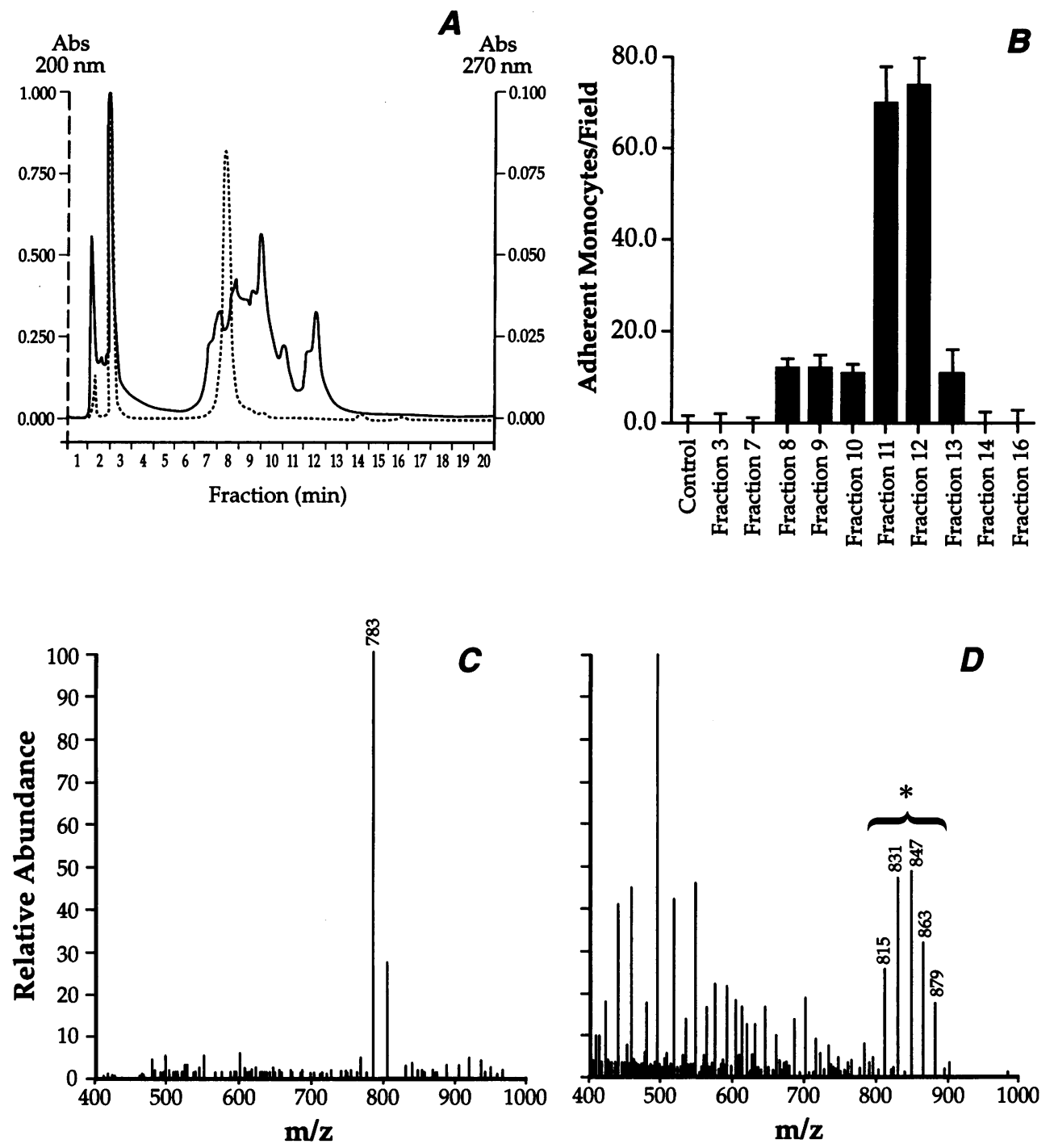

Figure 5. Characterization of bioactive lipids in Ox-PAPC. Authentic PAPC was allowed to autoxidize for $24 \mathrm{~h}$ at room temperature and was then analyzed by HPLC with detection at $200 \mathrm{~nm}$ (dotted line) and 270 $\mathrm{nm}$ ( solid line) $(A)$. Phospholipid fractions were collected under sterile conditions and tested for the abilty to induce monocyte binding to endothelial cells $(B)$. Fractions 8 $(C)$ and $11(D)$ (representing inactive and active fractions, respecively) were analyzed by fast atom bombardment-mass spectrometry as. described in Methods. * Indicates cluster of ions corresponding to $\mathrm{m} /$ $\mathrm{z}$ greater than parent ion by multiples of 16 atomic mass units.

phosphatidylcholine species that have acquired $270 \mathrm{~nm}$ absorbance.

Biological activity of oxidized synthetic phospholipids. As described above, mild oxidation of LDL appears to decrease the abundance of arachidonic acid-containing phospholipids in LDL. We, therefore, tested the ability of oxidized PAPC (OxPAPC) to induce endothelial cells to bind monocytes. HPLC analysis of Ox-PAPC revealed the presence of $235 \mathrm{~nm}$ absorbing material eluting at $7.0 \mathrm{~min}$ (data not shown), a variety of $270 \mathrm{~nm}$ absorbing species eluting between 7.0 and $13.0 \mathrm{~min}$, and the presence of residual unoxidized PAPC ( $200 \mathrm{~nm})$ eluting at 8.0 min (Fig. $5 A$ ). Under these HPLC conditions unoxidized PAPC did not absorb at a wavelength greater than $223 \mathrm{~nm}$ and was not active in increasing monocyte binding (data not shown). HPLC fractions were collected from Ox-PAPC under sterile conditions and tested individually for the ability to induce endothelial cells to bind monocytes (Fig. $5 B$ ). Fractions 11 and 12 induced a significant increase in monocyte binding, however, fraction 7 which contained predominately $235 \mathrm{~nm}$ absorbing material and fraction 8 which contained predominately unoxidized PAPC did not cause a significant increase in monocyte binding to endothelial cells (Fig. $5 \mathrm{~B}$ ). A comparison of frac- tions 8 and 11 by FAB-MS revealed that fraction 8 (Fig. 5 $C$ ) contained predominately residual unoxidized PAPC at $\mathrm{m} / \mathrm{z}$ 783.0. The fractions containing bioactivity, fraction 11 (Fig. 5 $D$ ) and fraction 12 , contained a mixture of ions ranging in $\mathrm{m} /$ $\mathrm{z}$ from 815 to 879 separated by $\sim 16 \mathrm{D}$. These ions were weak or nonexistent in fractions without biological activity and were not detectable in fractions from unoxidized PAPC.

Effect of paraoxonase on oxidized-PAPC. Ox-PAPC $(1 \mathrm{mg})$ was resuspended in $1 \mathrm{ml}$ of PBS containing $1 \mathrm{mM}$ calcium and divided into two equal portions. One portion was treated as a sham and the other portion was incubated with PON $(5 \mu \mathrm{g} / \mathrm{ml})$ at $37^{\circ} \mathrm{C}$ for $14 \mathrm{~h}$. The sham treated Ox-PAPC induced a significant increase in monocyte binding to endothelial cells, however, the same preparation after treatment with PON was without biological activity (Fig. $6 A, P<0.001$ ). Phospholipids treated under the same conditions were extracted and analyzed by FABMS. Unoxidized PAPC (Fig. $6 \mathrm{~B}$ ) contained a major ion at $\mathrm{m} / \mathrm{z} 782.8$ corresponding to authentic PAPC (theoretical $\mathrm{m} / \mathrm{z}$ 783.1). Ox-PAPC contained some residual unoxidized PAPC $(\mathrm{m} / \mathrm{z} 782.8)$ but, in addition, contained ions of greater mass than that of authentic PAPC at $\mathrm{m} / \mathrm{z} 830.8$ and $\mathrm{m} / \mathrm{z} 846.8$ (Fig. $6 C$ ). These ions were likely derived from PAPC and repre- 



Figure 6. Effect of paraoxonase on Ox-PAPC. Authentic PAPC was allowed to autoxidize for $24 \mathrm{~h}$ at room temperature. The lipid residue was resuspended in PBS with $10 \mathrm{mM}$ calcium and divided between two test tubes. Purified rabbit PON $(5 \mu \mathrm{g} / \mathrm{ml})$ was added to one tube and the other was incubated in parallel as a sham for $16 \mathrm{~h}$ at $37^{\circ} \mathrm{C}$. RAEC were incubated with no additive (Control), sham-treated oxidized PAPC $(O x-P A P C)$, or PON-treated oxidized PAPC $(O x-P A P C+P O N)$ and then tested for monocyte binding $(A){ }^{*} P<0.001$. Phospholipids were extracted and analyzed by fast atom bombardment-mass spectrometry from unoxidized PAPC $(B)$, sham-treated Ox-PAPC ( $C)$, and PON-treated Ox-PAPC $(D)$.

sented $\mathrm{M}+\mathrm{H}^{+}+48.0$ and $\mathrm{M}+\mathrm{H}^{+}+64.0$, due to the addition of three and four oxygen atoms, respectively, to PAPC. After treatment with PON $(5 \mu \mathrm{g} / \mathrm{ml})$ for $14 \mathrm{~h}$ at $37^{\circ} \mathrm{C}$ the higher molecular weight ions were completely absent (Fig. $6 \mathrm{D}$ ). These results indicated that paraoxonase destroyed phospholipids containing multioxygenated PUFA.

Mass spectrometry of $M M-L D L$. Lipids were extracted from coculture modified LDL and native LDL from the same donor and analyzed by preparative HPLC. Three fractions were collected that encompassed the region of biological activity evident in Fig. 5. Fraction 2 contained $\sim 80 \%$ of the biological activity (i.e., induction of monocyte binding) (data not shown). Each fraction was resuspended in $1 \mathrm{ml}$ of solvent and $20 \mu \mathrm{l}$ was injected sequentially into an electrospray mass spectrometer. Reconstructed selected ion monitoring was then conducted to determine the relative abundance of ions with $\mathrm{m} / \mathrm{z} 831$ and 847 . The signal from each fraction ( 1 through 3 ) in N-LDL (Fig. 5 $A$ ) were subtracted from respective fractions in MM-LDL (Fig. $5 B$ ) and the differential chromatogram shown in Fig. $5 C$ (MM-
LDL minus N-LDL). The total abundance of these ions in the fractions from MM-LDL (Fig. $5 B$ ) was approximately three times that seen in native LDL (Fig. $5 A$ ). The ion with $\mathrm{m} / \mathrm{z}$ 831 showed a distribution that paralleled the biological activity in the three fractions. The ion with $\mathrm{m} / \mathrm{z} 847$ was present in approximately equal abundance in fractions 1 and 2 . Since the biological activity of fraction 1 was less than that of fraction 2 , the data suggest that most of the biological activity may have been associated with the ion with $\mathrm{m} / \mathrm{z} 831$ that eluted in fraction 2. Similar results were obtained from analysis for oxidized arachidonic acid-containing phospholipids with stearic acid at the $s n-1$ position (data not shown). These data, taken together, strongly suggest that oxygenated phospholipids contribute to the biological activity of MM-LDL.

\section{Discussion}

This manuscript is the first publication to document an effect of paraoxonase on biologically active lipids in oxidatively modi- 
A

$N-L D L$
B

$M M-L D L$

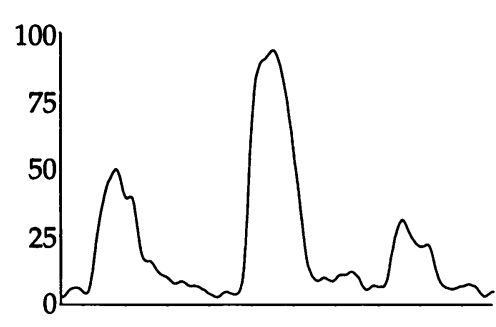

c

MM-LDL minus $N-L D L$
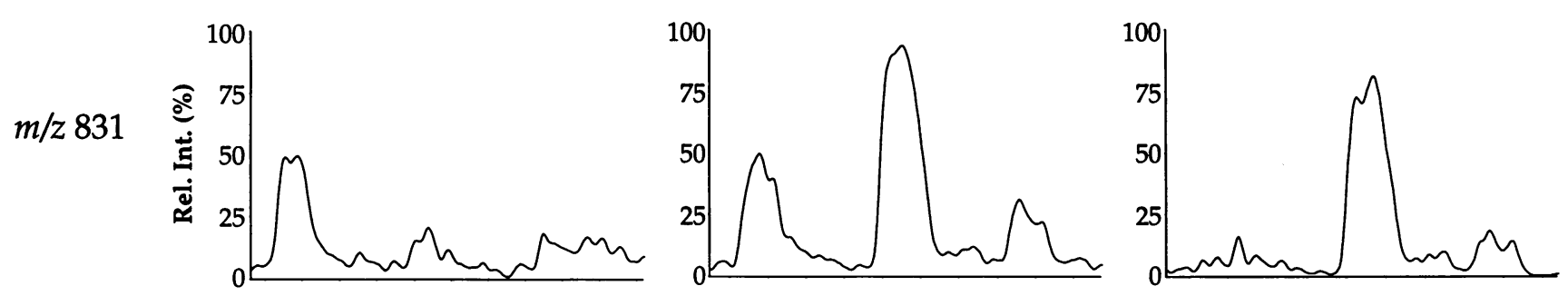

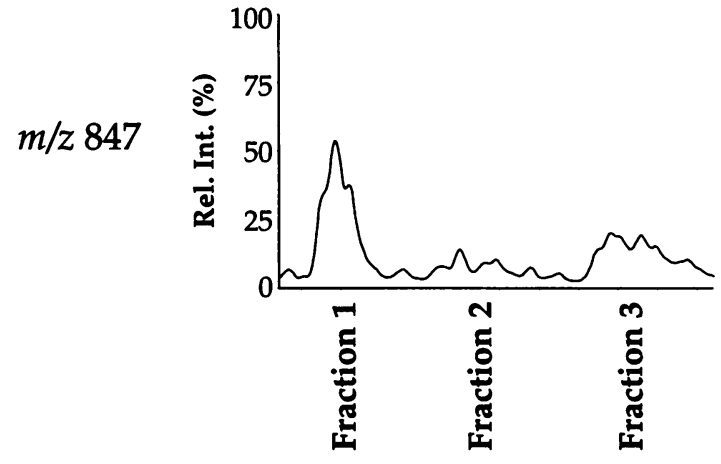

Time

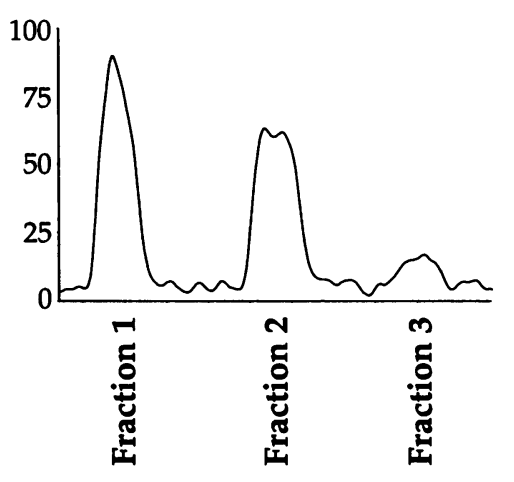

Time



Figure 7. Presence of $\mathrm{m} / \mathrm{z} 831$ and 847 ions in MM-LDL. Lipids were extracted from LDL before $(N-L D L)$ and after $(M M-L D L)$ incubation with human artery wall cells in Ham's F10 medium for $8 \mathrm{~h}$ at $37^{\circ} \mathrm{C}$. Lipids were separated by preparative HPLC and three identical fractions were collected in the period during which biologically active phospholipids were eluting (see Fig. $5 \mathrm{~A}$ ). Each of the three fractions was injected sequentially into the mass spectrometer spaced by an interval sufficiently long for the ion count from the previous injection to return to baseline. Reconstituted selected ion chromatograms were produced from the series of injections of native LDL fractions $(A)$ and MM-LDL fractions $(B)$ for $\mathrm{m} / \mathrm{z}=831$ and 847. Computer software was used to create differential reconstructed ion chromatograms of $\mathrm{m} / \mathrm{z} 831$ and 847 for MM-LDL minus N-LDL $(C)$. All chromatograms were then smoothed for clarity. Rel. Int. (\%), Relative height $(\%)$ relative to the highest peak of all panels.

fied lipoproteins. The results of this study provide several lines of evidence suggesting that biologically active lipids in MMLDL are derived from arachidonic acid-containing phosphatidylcholine produced by oxidation. ( $a$ ) We invariably observe a selective decrease in the HPLC peak corresponding to arachidonic acid-containing phosphatidylcholine (PC-1) after mild oxidation (Fig. 3). Based on this, the synthetic phospholipid PAPC was used as a surrogate for the precursor of the biologically active lipid in MM-LDL in some experiments. (b) Oxidized PAPC induced endothelial cells to bind monocytes. (c) By mass spectrometry of HPLC-isolated fractions (Fig. 5) we found that two of the predominate ions present in the biologically active fractions of Ox-PAPC $(\mathrm{m} / \mathrm{z} 831$ and 847$)$ were also found in the biologically active fractions of MM-LDL (Fig. 7).

The molecular mass of these phospholipids are consistent with nonenzymatically formed, arachidonic acid-derived, eicosanoids at the $s n-2$ position of PAPC. Most of these eicosanoids possess absorbance maxima in the $265-290 \mathrm{~nm}$ range, however the precise molecular structure of the molecules present in our FAB-MS spectra has not yet been determined. An example of this phenomenon is phospholipid-bound $F_{2}$-isoprostanes $(\mathrm{m} / \mathrm{z}$ 831 ) which have been shown to be present in oxidized LDL (43). Isoprostanes have also been shown to possess biological activity on smooth muscle cells $(44,45)$. Initial studies in our laboratory suggest that the free-acid form is active in inducing monocyte binding to human aortic endothelial cells (data not shown).

The mechanism by which PON protects against the action of MM-LDL appears to be associated with destruction of oxidized phospholipids in MM-LDL. PON destroyed multioxygenated PAPC molecules (Fig. $6 \mathrm{D}$ ) in Ox-PAPC and decreased the amount of $270 \mathrm{~nm}$ absorbance of phospholipids in MM-LDL (Fig. 4). To account for both of these observations we would hypothesize that the substrate for PON is an arachidonic acidcontaining phospholipid to which three to four oxygens have been added in an orientation that alters the spectral absorbance of the molecule. The presence of $270 \mathrm{~nm}$ absorbance may be the result of the formation of carbonyl groups or the addition of hydroxyl or hydroperoxyl groups at the 5 and 12 carbons of arachidonic acid forming a conjugated triene structure characteristic of leukotrienes. Any of these compounds may decompose to form short chain acyl residues at the $s n$ - 2 position such as 5-oxovalerate which have been shown to be biologically active (46) and are substrates for PAF-AH $(47,48)$. Thus it is possible that both phospholipids containing oxygenated and cyclized arachidonic acid as well as fragmentation products of arachidonic acid represent biologically active lipids. Initial analyses of Ox-PAPC by liquid chromatography-mass spectrometry indicate that both fragmented PAPC and the multioxy- 


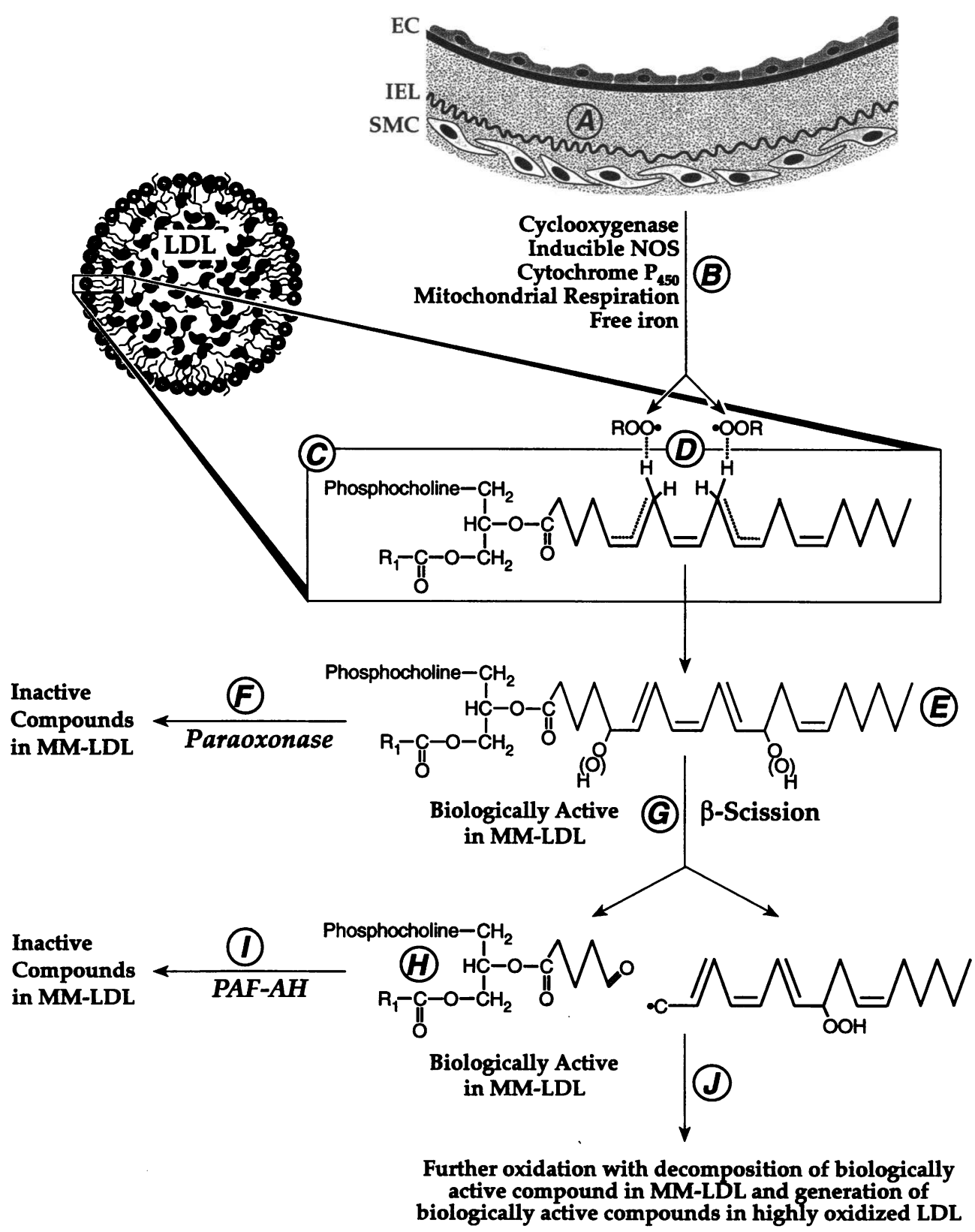

Figure 8. Hypothetical model for the mechanism by which HDL destroys biologically active lipids in MM-LDL. Reactive oxygens species may be formed in the artery wall $(A)$ in areas sequestered from plasma antioxidants by a variety of possible mechanisms, some of which may involve cyclooxygenase, lipoxygenase, inducible nitric oxide synthase, cytochrome $\mathrm{P}_{450}$, mitochondrial respiration, or free iron $(B)$. These oxygen radicals may then "seed" LDL within the subendothelial space by oxidation of phospholipids in LDL $(C)$.

This process involves abstraction of hydrogen atoms from bis-allylic methylenes $(D)$. Addition of molecular oxygen at multiple sites may generate multi-oxygenated phospholipids $(E)$ which may be substrates for PON in HDL $(F)$. In cases where PON concentrations are low or depleted or where lipid peroxide levels are excessive, oxidized phospholipids may undergo oxidative fragmentation $(G)$ to form molecules $(H)$ which evoke the characteristic inflammatory responses in endothelial cells induced by MM-LDL. These oxidatively fragmented phospholipids may then be substrates for the second line of defence, PAFAH (I). PAF-AH hydrolyzes these biologically active lipids into molecules which do not evoke the characteristics inflammatory responses in endothelial cells induced by MM-LDL. Further oxidative decomposition of lipids in LDL, including cholesteryl esters, leads to the deposition of highly oxidized LDL $(J)$ present in the necrotic core of advanced atherosclerotic lesion. EC, endothelial cells; IEL, internal elastic lamina; SMC, smooth muscle cells; Inducible NOS, inducible nitric oxide synthase; $\cdot O O R$, lipoperoxides.

genated PAPC molecules reported here are present in some fractions that induce monocyte-endothelial interactions (data not shown). A method of complete separation of these two lipid classes is being developed.

The current and past (32) studies from our group suggest that both PAF-AH and paraoxonase can destroy active lipids in MM-LDL and that their effects are additive. Several lines of evidence suggest that there are differences in the action of the two enzymes. In addition, during copper-induced oxidation of LDL, PAF-AH inhibits apolipoprotein $\mathrm{B}_{100}$ modification and conjugated diene formation but has no effect on thiobarbituric acid reactive substances (TBARS) (reference 49 and Prescott,
S. M., personal communication) however, PON inhibits both the production of lipoperoxides and TBARS (31). Treatment of MM-LDL with PAF-AH resulted in a decrease in $234 \mathrm{~nm}$ absorbance (reference 32, Fig. 5), while PON had no effect on $234 \mathrm{~nm}$ absorbance but resulted in a decrease in $270 \mathrm{~nm}$ absorbance (Fig. 4). Furthermore, PAF-AH has been shown to act on molecules with nine carbons or less at the $s n-2$ position (46) while PON has been shown in the current study to act on derivatives with longer chains.

The experiments shown in Fig. 1 represent an HDL preparation in which PON and PAF-AH activities made approximately equal contributions to the protection afforded by HDL. In the 
course of these studies we have observed that the protection afforded by HDL taken from some subject is more dependent on PON activity and in others more depended on PAF-AH activity. We have measured the ratio of activity of PAF-AH/ PON in $\sim 20 \mathrm{HDL}$ preparations and have found considerable variance in the ratios obtained in HDL from different individuals (data not shown). Based on data from our laboratory and others we propose the hypothetical model shown in Fig. 8 which illustrates that phospholipids with both long and short chains at the $s n-2$ positions may induce monocyte-endothelial interactions. PAF-AH can hydrolyze the short chain derivative while PON hydrolyzes long chain derivatives.

Changes in PON activity may occur independently of changes in HDL cholesterol or apolipoprotein A-I (29). In the current study we have shown that treatment of MM-LDL with PON and HDL-associated esterase for $14 \mathrm{~h}$ inhibited its ability to induce monocyte-endothelial interactions. Incubating MMLDL in a test tube with HDL for $14 \mathrm{~h}$ also reduced the ability of the MM-LDL to induce monocyte-endothelial interactions but shorter coincubation times of HDL with MM-LDL $(<6 \mathrm{~h})$ like those used previously (9) were not sufficient to destroy the biological activity (data not shown). We previously reported (9) that phospholipid liposomes (but not purified apo AI) prevented the biological activity of coculture modified LDL. Since these liposomes did not contain either PON or PAF-AH before addition to the cocultures the possibility exists that these liposomes served as a sink for the biologically active lipids of the kind shown in Fig. 8. These lipids may have been sequestered in the liposomes in such as way as to prevent their interaction with the coculture cells in a manner necessary to trigger the expression of the genes that induce monocyte binding and migration. The protective effect of HDL may not be dependent on the absolute levels of HDL cholesterol in the blood but rather the abundance of HDL particles which contain protective enzymes relative to the concentration of oxidized LDL proximate to the artery wall cells. This ratio is determined by both genetic and environmental factors. Genetic determinants may include plasma levels and isoforms of PON and PAF-AH. Environmental influences may include factors that augment the accumulation of LDL in the subendothelial space (e.g., hypercholesterolemia and apolipoprotein [a]) as well as factors which increase oxidative stress (e.g., smoking and diabetes). The findings presented herein could, in part, help to explain why some individuals with low LDL/HDL ratios experience clinical events while other individuals with high LDL/HDL ratios live free from clinical events resulting from vascular disease.

\section{Acknowledgments}

The authors thank Drs. A. Jake Lusis, George Popják, Peter A. Edwards, Farhad Parhami, Mary C. Territo, Brian J. Van Lenten, Balz Frei, Devendra K. Vora, Sampath Parthasarathy, Seppo Ylä-Herttuala, Alan Chait, Jay W. Heinecke, Alex Sevanian, and Laurie McLeod for valuable discussions and suggestions; Cynthia Harper, Alan C. Wagner, Ken Conklin, Thao Nguyen, and Leslie Young for expert technical assistance; and the members of the UCLA Heart Transplant Team for collecting the aortic specimens.

This work was supported by the U.S. Public Health Services grants HL-30568, HL-07386, and RR 865; by the Laubisch, Rachel Israel Berro, and M.K. Grey Funds; the Cigarette and Tobacco Surtax Fund of the State of California through the Tobacco-Related Disease Research Program at the University of California; and GM 46979 (B.N. La Du).

\section{References}

1. Steinberg, D., S. Parthasarathy, T. E. Carew, J. C. Khoo, and J. L. Witztum 1989. Beyond cholesterol. Modifications of low density lipoproteins that increase its atherogenicity. N. Engl. J. Med. 320:915-924.

2. Witztum, J. L., and D. Steinberg. 1991. Role of oxidized low density lipoprotein in atherogenesis. J. Clin. Invest. 88:1785-1792.

3. Berliner, J. A., and M. E. Haberland. 1991. Role of oxidized low density lipoprotein in atherogenesis. Curr. Opin. Lipidol. 4:373-381.

4. Parthasarathy, S. 1994. Mechanisms of oxidation of LDL. In modified lipoproteins in the pathogenesis of atherosclerosis. S. Parthasarathy, editor. R. G. Landes Co., Austin, TX. 91-119.

5. Witztum, J. L. 1994. The oxidation hypothesis of atherosclerosis. Lancet. 344:793-795.

6. Parthasarathy, S. 1994. Mechanism(s) of cell-mediated oxidation of low density lipoprotein. In Free Radicals in the Environment, Medicine and Toxicology. H. Nohl, H. Esterbauer, and C. Rice Evans, editors. Richelieu Press, London. 163-179.

7. Parhami, F., Z.-T. Fang, A. M. Fogelman, A. Andalibi, M. C. Territo, and J. A. Berliner. 1993. Minimally modified low density lipoprotein-induced inflammatory responses in endothelial cells are mediated by cyclic adenosine monophosphate. J. Clin. Invest. 92:471-478.

8. Cushing, S. D., J. A. Berliner, A. J. Valente, M. C. Territo, M. Navab, F. Parhami, R. Gerrity, C. J. Schwartz, and A. M. Fogelman. 1990. Minimally modified low density lipoprotein induces monocyte chemotactic protein 1 in human endothelial cells and smooth muscle cells. Proc. Natl. Acad. Sci. USA. 87:5134-5138.

9. Navab, M., S. S. Imes, G. P. Hough, S. Y. Hama, L. A. Ross, R. W. Bork A. J. Valente, J. A. Berliner, D. C. Drinkwater, H. Laks, and A. M. Fogelman. 1991. Monocyte transmigration induced by modification of low density lipoprotein in cocultures of human aortic wall cells is due to induction of monocyte chemotactic protein 1 synthesis and is abolished by high density lipoprotein. J. Clin. Invest. 88:2039-2046.

10. Berliner, J. A., M. C. Territo, A. Sevanian, S. Ramin, J. A. Kim, B. Bamshad, M. Esterson, and A. M. Fogelman. 1990. Minimally modified low density lipoprotein stimulates monocyte endothelial interactions. J. Clin. Invest. 85:1260-1266.

11. Rajavashisth, T. B., A. Andalibi, M. C. Territo, J. A. Berliner, M. Navab, A. M. Fogelman, and A. J. Lusis. 1990. Induction of endothelial cell expression of granulocyte and macrophage colony-stimulating factors by modified low density lipoproteins. Nature (Lond.). 344:254-257.

12. Cathcart, M. K., A. K. NcNally, D. W. Morel, and G. M. Chisolm. 1989. Superoxide anion participation in human monocyte-mediated oxidation of low density lipoprotein and conversion of low density lipoprotein to a cytotoxin. $J$. Immunol. 142:1963-1969.

13. Cathcart, M. D., A. K. McNally, and G. M. Chisolm. 1991. Lipoxygenasemediated transformation of human low density lipoprotein to an oxidized and cytotoxic complex. J. Lipid Res. 32:63-70.

14. Hessler, J. R., A. L. Robertson, Jr., G. M. Chisolm. 1979. LDL-induced cytotoxicity and its inhibition by HDL in human vascular smooth muscle and endothelial cells in culture. Atherosclerosis. 32:213-229.

15. Parthasarathy, S., D. J. Printz, D. Boyd, L. Joy, and D. Steinberg. 1986. Macrophage oxidation of low density lipoprotein generates a modified form recognized by the scavenger receptor. Arteriosclerosis. 6:505-510.

16. Henriksen, T., E. M. Mahoney, and D. Steinberg. 1983. Enhanced macrophage degradation of biologically modified low density lipoprotein. Atherosclerosis. 3:149-159.

17. Brown, M. S., and J. L. Goldstein. 1990. Scavenging for receptors. Nature (Lond.). 343:508-509.

18. Gordon, D. J., J. L. Probstfield, R. J. Garrison, J. D. Neaton, W. P. Castelli, J. D. Jacobs, Jr., S. Bangdiwala, and H. A. Tyroler. 1989. High-density lipoprotein cholesterol and cardiovascular disease. Circulation. 79:8-15.

19. Gordon, T., W. P. Castelli, M. C. Hjortland, W. B. Kannel, and T. R Dawber. 1977. High density lipoprotein as a protective factor against coronary heart disease. Am. J. Med. 62:707-714.

20. Parthasarathy, S., J. Barnett, and L. G. Fong. 1990. High density lipoprotein inhibits the oxidative modification of low density lipoprotein. Biochim. Biophys. Acta. 1044:275-283.

21. Maier, J. A. M., L. Barenghi, F. Pagani, S. Bradamante, P. Comi, and G. Ragnotti. 1994. The protective role of high-density lipoprotein on oxidized-lowdensity-lipoprotein-induced U937/endothelial cell interactions. Eur. J. Biochem. 221:35-41.

22. Haberland, M. E., D. Fong, and L. Chen. 1988. Malondialdehyde altered protein occurs in atheroma of WHHL rabbits. Science (Wash. DC) 241:215-218.

23. Palinski, W., M. E. Rosenfeld, S. Ylä-Herttuala, G. C. Gurtner, S. S. Socher, S. W. Butler, S. Parthasarathy, T. E. Carew, D. Steinberg, and J. L. Witztum. 1989. Low density lipoprotein undergoes oxidative modification in vivo. Proc. Natl. Acad. Sci. USA. 86:1372-1376.

24. Ylä-Herttuala, S., W. Palinski, M. E. Rosenfeld, S. Parthasarathy, T. E. 
Carew, S. Butler, J. L. Witztum, and D. Steinberg. 1989. Evidence for the presence of oxidatively modified low density lipoprotein in atherosclerotic lesions of rabbit and man. J. Clin. Invest. 84:1086-1095.

25. La Du, B. N. 1992. Human serum paraoxonase/arylesterase. In Pharmacogenetics of Drug Metabolism. W. Kalow, editor. Pergamon Press, Inc., New York $51-91$.

26. Chemnitius, J.-M., H. Losch, K. Losch, and R. Zech. 1983. Organophosphate detoxicating hydrolases in different vertebrate species. Comp. Biochem. Physiol. C. 76:85-93.

27. Saha, N., A. C. Roy, S. H. Teo, J. S. Tay, and S. S. Ratnam. 1991. Influence of serum paraoxonase polymorphism on serum lipids and apolipoproteins. Clin. Genet. 40:277-282.

28. Mackness, M. I., S. Arrol, C. A. Abbott, and P. N. Durriton. 1993. Is paraoxonase related to atheroslerosis. Chem. Biol. Interac. 87:161-171.

29. Mackness, M. I., C. H. Walker, and L. A. Carlson. 1987. Low 'A' esterase activity in serum of patients with fishe eye disease. Clin. Chem. 35:587-588.

30. Mackness, M. I. 1989. Possible medical significance of human serum ' $\dot{A}$ ' esterases, In Enzymes Hydrolyzing Organophosphorus Compounds. E. Reiner,

W. N. Aldridge, and F. C. G. Hoskin, editors. 202-213.

31. Mackness, M. I., S. Arrol, and P. N. Durrington. 1991. Paraoxonase prevents accumulation of lipoperoxides in low density lipoprotein. FEBS Lett. 286:152-154.

32. Watson, A. D., M. Navab, S. Y. Hama, A. Sevanian, S. M. Prescott, D. M. Stafforini, T. M. McIntyre, B. N. La Du, A. M. Fogelman, and J. A. Berliner. 1995. Effect of platelet activating factor-acetylhydrolase on the production and activity of mildly oxidized low density lipoprotein. $J$. Clin. Invest. 95:774-782.

33. Gan, K. N., A. Smolen, H. W. Ecderson, and B. N. La Du. 1991. Purification of human serum paraoxonase/arylesterase. Evidence for one esterase catalyzing both activities. Drug Metab. Dispos. 19:100-106.

34. Rosenthal, A. M., and A. I. Gotlieb. 1990. Microvascular endothelial cells from porcine aorta. In Cell Culture Techniques in Heart and Vessel Research. H. M. Piper, editor. Springer-Verlag, Berlin. 117-129.

35. Navab, M., G. P. Hough, L. W. Stevenson, D. C. Drinkwater, H. Laks, and A. M. Fogelman. 1988. Monocyte migration into the subendothelial space of a coculture of adult human aortic endothelial and smooth muscle cells. J. Clin. Invest. 82:1853-1863.

36. Fogelman, A. M., K. Sykes, B. J. Van Lenten, M. C. Territo, and J. A. Berliner. 1988. Modification of the Recalde method for the isolation of human monocytes. J. Lipid Res. 29:1243-1247.
37. Havel, R. J., H. A. Eder, and J. H. Bragdon. 1955. The distribution and chemical composition of ultracentrifugally separated lipoproteins of human serum. J. Clin. Invest. 43:1345-1353.

38. Bligh, E. G., and W. J. Dyer. 1959. A rapid method of total lipid extraction and purification. Can. J. Biochem. Physiol. 37:911-917.

39. Kaluzny, M. A., L. A. Duncan, M. V. Merritt, and D. E. Epps. 1985. Rapid separation of lipid classes in high yield and purity using bonded phase columns. J. Lipid Res. 26:135-140.

40. Stafforini, D. M., T. M. McIntyre, and S. M. Prescott. 1990. Platelet activating factor acetylhydrolase from human plasma. Methods Enzymol. 187:344-357.

41. Simeon, V., and E. Pavkovíc. (1993) Heat inactivation of paraoxonase and arylesterase activities in human and rabbit serum. Chem. Biol. Interac. 87:103-107.

42. Lowry, O. H., M. J. Rosebrough, A. L. Farr, and R. J. Randall. 1951. Protein measurement with the Folin Phenol reagent. J. Biol. Chem. 193:265-275.

43. Gopaul, N. K., J. Nourooz-Zadeh, A. I. Mallet, and E. E. Anggard. 1994. Formation of $\mathrm{F}_{2}$-isoprostanes during aortic endothelial cell-mediated oxidation of low density lipoprotein. FEBS Lett. 348:297-300.

44. Banerjee, M., K. H. Kang, J. D. Morrow, L. J. Roberts, and J. H. Newman. 1992. Effects of a novel prostaglandin, 8-epi-PGF PG $_{2 \alpha}$ in rabbit lung in situ. Am. J. Physiol. 263:H660-H663.

45. Fukunaga, M., K. Takahashi, and K. F. Badr. 1993. Vascular smooth muscle actions and receptor interactions of 8-iso-prostaglandin $E_{2}$ and $E_{2}$-isoprostane. Biochim. Biophys. Res. Commun. 195:507-515.

46. Heery, J. M. M. Kozak, D. M. Stafforini, G. A. Zimmerman, T. M. McIntyre, and S. M. Prescott. 1993. Atherogenic Effects of Lipids from Oxidized LDL. Circulation. 88:I-562. (Abstr.)

47. Stremler, K. E., D. M. Stafforini, S. M. Prescott, and T. M. McIntyre. 1991. Human plasma platelet-activating factor acetylhydrolase. Oxidiatively fragmented phospholipids as substrates. J. Biol. Chem. 266:11095-11103.

48. Stremler, K. E., D. M. Stafforini, S. M. Prescott, G. A. Zimmerman, and T. M. McIntyre. 1989. An oxidized derivative of phosphatidylcholine is a substrate for the platelet activaing factor acetylhydrolase from human plasma. J. Biol. Chem. 264:5331-5334.

49. Stafforini, D. M., G. A. Zimmerman, T. M. McIntyre, and S. M. Prescott. 1992. The platelet activating factor acetylhydrolase from human plasma prevents oxidative modification of low density lipoprotein. Trans. Assoc. Am. Phys. 105:44-63. 